\title{
Evaluating the effect of maternal health conditions on severe maternal morbidity adjusting for emergent cesarean delivery: A mediation analysis approach
}

\author{
Moshe Fridman ${ }^{1}$, Naomi H. Greene ${ }^{2}$, Lisa M. Korst ${ }^{3}$, Elizabeth Lawton ${ }^{4}$, Samia El Haj Ibrahim², Flojaune Griffin ${ }^{4}$, \\ Lisa Nicholas ${ }^{5}$, Kimberly D. Gregory*2,5,6 \\ ${ }^{1}$ AMF Consulting, Los Angeles, CA, USA \\ ${ }^{2}$ Department of Obstetrics and Gynecology, Cedars-Sinai Medical Center, Burns Allen Research Institute, Los Angeles, CA, USA \\ ${ }^{3}$ Childbirth Research Associates, Los Angeles, CA, USA \\ ${ }^{4}$ Maternal, Child and Adolescent Health Division, California Department of Public Health, Sacramento, CA, USA \\ ${ }^{5}$ Department of Obstetrics and Gynecology, David Geffen School of Medicine at UCLA, Los Angeles, CA, USA \\ ${ }^{6}$ Department of Community Health Sciences, Fielding School of Public Health at UCLA, Los Angeles, CA, USA
}

Received: November 11, 2015

DOI: $10.5430 /$ jer.v2n2p36
Accepted: December 17, 2015 Online Published: January 20, 2016

URL: http://dx.doi.org/10.5430/jer.v2n2p36

\begin{abstract}
The prevalence of pre-existing and gestational maternal health conditions is rising; affected women are at increased risk for both cesarean delivery (CD) and severe maternal morbidity (SMM). We estimated the increased risk of SMM associated with key maternal health conditions, and determined the extent to which it was directly associated with these conditions versus indirectly associated because of an increased risk of CD. Nulliparous, term, singleton, vertex (NTSV) gestations were identified among laboring women in California 2008-2010 hospital discharge datasets. Logistic regression models (stratified by younger vs. older women [ $\geq 35$ years]) were constructed for each condition: chronic/gestational diabetes mellitus (DM), chronic/gestational hypertension, obesity, heart disease, and mental health diagnoses. Using mediation analysis, the potential effect associated with each condition (exposure) on SMM (outcome) consisted of a direct effect and an indirect effect caused by modification of the risk of an emergent CD (mediator). Of 502,654 deliveries, 24.3\% had an emergent CD; 1.7\% had SMM, which was present in $1.6 \%$ of younger $v s .2 .2 \%$ of older mothers. The modeled odds ratios (ORs) for the direct effect on SMM were 2.00-2.67 for any hypertension, 0.78 for obesity in younger women, 6.57-7.97 for heart disease, and 1.43-1.58 for mental health diagnoses. No direct effect was identified for DM or obesity in older women. The ORs for the indirect effect were low, ranging from 0.94-1.11 for all models. For women laboring with NTSV gestations where key maternal health conditions were present, the risk of SMM mediated by an emergent $\mathrm{CD}$ was low, relative to the direct risk.
\end{abstract}

Key Words: Emergent cesarean delivery, Severe maternal morbidity, Mediation analysis

\section{INTRODUCTION}

The American College of Obstetricians and Gynecologists (ACOG) and the Society for Maternal-Fetal Medicine
(SMFM) recently published a joint statement proposing the development of standards for maternal risk-appropriate care. ${ }^{[1]}$ This proposal comes amid documentation of con-

*Correspondence: Kimberly D. Gregory; Email: Kimberly.gregory@cshs.org; Address: Department of Obstetrics and Gynecology, Cedars-Sinai Medical Center 8700 W. 3rd St., 160 West Tower, Los Angeles, CA 90048, USA. 
tinuing national increases in maternal mortality and severe maternal morbidity (e.g., renal failure, adult respiratory distress syndrome, and shock). ${ }^{[2-6]}$ The premise of the proposed regionalization infrastructure is that women who are most at risk for experiencing severe maternal morbidity should receive antenatal referrals to facilities with the optimal resources and personnel for their care. Chronic disease (e.g., chronic hypertension, diabetes mellitus [DM], heart disease), and gestational disease (e.g., gestational DM [GDM] and preeclampsia) put women at risk for severe maternal morbidity. ${ }^{[5]}$ With the exception of the declining trend in heart disease, the prevalence of these pre-existing and gestational conditions has been increasing. ${ }^{[9,10]}$ Obesity, which has also been increasing, ${ }^{[9,11]}$ is often associated with these conditions and is also a risk factor for severe maternal morbidity. ${ }^{[8,12,13]}$ Furthermore, mental health diagnoses are now reported more frequently during childbirth admissions, ${ }^{[10]}$ and appear to put women at risk for severe maternal morbidity. ${ }^{[8]}$ These pre-existing and gestational conditions have been studied in various combinations, yet because they are potential candidates for triggering antenatal transfer to sophisticated childbirth facilities, it is important to quantify the risk associated with each of them. Although the potential to avoid severe maternal morbidity may be limited ${ }^{[14]}$ there may still be opportunities for primary and secondary prevention, particularly if these conditions are recognized early and women have access to risk-appropriate care.

Estimates of the association of severe maternal morbidity and these pre-existing and gestational conditions have generally not taken the route of delivery into account. Women undergoing cesarean delivery (CD) are at increased risk for intra-operative and postpartum complications, and these risks are greater if a $\mathrm{CD}$ is performed after labor has occurred (e.g., failed vaginal birth or emergent CD). ${ }^{[15-17]}$ Emergent CD (hereafter referred to as $\mathrm{CD}$ for simplicity) itself has been associated with increased rates of severe maternal morbidity, ${ }^{[7,12,18]}$ and the degree to which the risk of severe maternal morbidity is affected by $\mathrm{CD}$ in the presence of key maternal health conditions is unknown.

The estimation of the risk of these pre-existing and gestational conditions is complicated because CD not only is associated with them but also because $\mathrm{CD}$ is itself a causal factor for severe maternal morbidity. Treating $\mathrm{CD}$ as an independent risk factor would introduce collinearity resulting in underestimation of the effect of pre-existing and gestational conditions. ${ }^{[19]}$ Rather, there exists both a direct effect of the conditions themselves, and an indirect effect of the conditions that is mediated through the performance of a $\mathrm{CD}$ (see Figure 1). Most studies correctly ignore the role of $\mathrm{CD}$ and report the total effect of these conditions, which is the product of the direct effect and the indirect effect. If the indirect effect of these conditions through CD does not contribute greatly to the total effect, then this distinction may be negligible, and reporting of the total risk, adequate. However, if the indirect effect were large, this could impact clinical decision-making regarding the use of $\mathrm{CD}$ in affected patients.

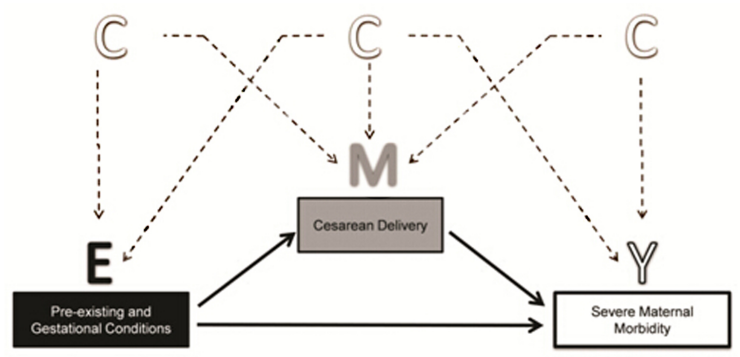

Figure 1. Conceptual model for the risk of severe maternal complication from childbirth. Pre-existing and Gestational Conditions $=\mathrm{E}($ Exposure $)$, Cesarean Delivery $=\mathrm{M}$ (Mediator), Severe Maternal Morbidity = Y (Outcome), Confounders $=\mathrm{C}$ (Vector of Covariates) ${ }^{*}$

*The same set of potential confounders were used in the equations for both the direct and indirect effects; it includes: control variables: maternal age, racelethnicity, education, insurance status, prenatal care status, year of delivery; obstetrical conditions: placenta previa, premature rupture of membranes (PROM), postterm pregnancy, cord prolapse, cord entanglement, antepartum bleeding/abruption, isoimmune disease, soft tissue conditions (i.e., disorders of the organs and soft tissue of the pelvis); fetal conditions: polyhydramnios, oligohydramnios, intrauterine growth restriction, excessive fetal growth; and intrapartum conditions: fetal distress and dystocia; other pre-existing conditions were: Herpes virus infection, and presence of hepatic or renal disease.

Here, using a population of laboring women, our objective was to estimate the total effect (TE) of several key preexisting and gestational conditions on severe maternal morbidity, and determine the direct effect (DE) of the condition itself, and the indirect effect (IE) of the condition as mediated through $\mathrm{CD}$, where $\mathrm{TE}=\mathrm{DE} \times \mathrm{IE}$.

\section{Methods}

\subsection{Data}

The study was approved by the California Health and Human Services Agency Committee for the Protection of Human Subjects (protocol 12-08-0596) and by the Cedars-Sinai Medical Center Institutional Review Board (protocol 00029744). Data obtained from California 2008-2010 linked maternal and neonatal hospital discharge datasets were aggregated. These datasets are linked to vital statistics data and include over $97 \%$ of California births. ${ }^{[20]}$ For improved interpretabil- 
ity of the analyses, we selected a study population of nulliparous, term ( $\geq 37$ weeks), singleton, vertex (NTSV) inborn, liveborn gestations. The NTSV population is a commonly used denominator for the assessment of the quality of childbirth services as it controls for key risk factors associated with maternal outcomes and use of $\mathrm{CD} \cdot{ }^{[21]}$ Because many women in the NTSV population undergo elective (i.e., nonlaboring) $\mathrm{CD}$ for other obstetrical, fetal or maternal complications, or upon maternal request, this population was further limited to women undergoing labor. The presence of labor was defined by a previously validated algorithm using ICD-9-CM codes, ${ }^{[22]}$ with some minor modifications (see Table 1).

Table 1. Administrative codes used to identify the presence of labor (in addition to vaginal delivery)

\begin{tabular}{|c|c|}
\hline $\begin{array}{l}\text { ICD-9-CM } \\
\text { Diagnostic Code }\end{array}$ & ICD-9-CM Code Description \\
\hline 659.7 & Abnormality in fetal heart rate or rhythm \\
\hline 661 & Abnormality of forces of labor \\
\hline 652.1 & $\begin{array}{l}\text { Breech or other malpresentation successfully converted to } \\
\text { cephalic presentation }\end{array}$ \\
\hline 658.2 & $\begin{array}{l}\text { Delayed delivery after spontaneous or unspecified rupture of } \\
\text { membranes }\end{array}$ \\
\hline 653 & Disproportion in pregnancy labor and delivery \\
\hline 644.2 & Early onset of delivery \\
\hline 659.0 & Failed mechanical induction of labor \\
\hline 659.1 & Failed medical or unspecified induction of labor \\
\hline 656.3 & Fetal distress affecting management of mother \\
\hline 659.3 & Generalized infection during labor \\
\hline 658.4 & Infection of amniotic cavity \\
\hline 662 & Long labor \\
\hline 659.2 & Maternal pyrexia during labor unspecified \\
\hline 660 & Obstructed labor \\
\hline 658.1 & Premature rupture of membranes \\
\hline 663.0 & Prolapse of cord complicating labor and delivery \\
\hline \multicolumn{2}{|l|}{ ICD-9-CM } \\
\hline 73.01 & Induction of labor by artificial rupture of membranes \\
\hline 73.4 & Medical induction of labor \\
\hline 96.49 & Other genitourinary instillation \\
\hline 73.1 & Other surgical induction of labor \\
\hline
\end{tabular}

We used vital statistics data to identify parity, gestational age, and maternal body mass index (BMI). Preterm deliveries, defined based on obstetrical estimates of gestational age between 24 and 36 completed weeks, were excluded. Last menstrual period estimates were used if obstetrical estimates were missing. We used hospital discharge data to identify all other clinical conditions. Multiple gestations were identified based on International Classification of Diseases, Version 9, Clinical Modification (ICD-9-CM) codes V272, V273, V274, V275, V276, V277, or 651.xx; malpresentation was based on code 652.xx (except 652.1x or 652.5x).

\subsection{Outcome, mediator and exposures}

This analysis focused on the effects of key pre-existing and gestational conditions on severe maternal morbidity. Severe maternal morbidity is a composite measure of morbidity, and includes maternal mortality, life-threatening conditions, and the use of life-saving procedures at the time of labor and delivery. Methods for classifying severe maternal morbidity from hospital discharge data have been documented in the obstetrical literature, ${ }^{[3]}$ including a severe maternal morbidity definition that we have published previously ${ }^{[22]}$ and modified slightly for purposes of this analysis. For the ICD-9-CM codes used in the definition, please see Table 2.

Table 2. Administrative codes used to define severe maternal morbidity

\begin{tabular}{|c|c|}
\hline Severe maternal morbidity & ICD-9-CM* codes \\
\hline Anesthesia complication & $668.0,668.1,668.2$ \\
\hline Cerebral hemorrhage & $348.5,430-434,436,437.2,671.5,674.0,780.01,780.03$ \\
\hline Hysterectomy (procedure codes) & $68.3-68.7,68.9$ \\
\hline $\begin{array}{l}\text { Maternal infection (All codes } \\
\text { must be associated with length of } \\
\text { stay } \geq 4 \text { days) }\end{array}$ & $038,785.52,995.91,995.92$ \\
\hline Maternal death & Maternal death variable \\
\hline Obstetrical Shock & $669.1,669.2$ \\
\hline Other maternal morbidity & $\begin{array}{l}286.6,669.4,997.1,570,584,586,669.3,669.4,671.4 \text {, } \\
674.8,997.1,998.0,998.1,998.2,998.3,998.4,998.5 \text {, } \\
998.6,998.7,998.81,998.83,998.89,998.9\end{array}$ \\
\hline Pulmonary embolism & $415.11,415.19,673.0,673.1,673.2,673.3,673.8$ \\
\hline Transfusion (procedure codes) & $99.00,99.03,99.04$ \\
\hline Uterine rupture & 665.1 \\
\hline $\begin{array}{l}\text { Additional potential maternal } \\
\text { intensive care unit admission }\end{array}$ & $518,674.5$ \\
\hline $\begin{array}{l}\text { Additional potential maternal } \\
\text { intensive care unit admission } \\
\text { (procedure codes) }\end{array}$ & $\begin{array}{l}31.1,38.86,38.88,39.95,54.11,54.12,54.19,89.6,96.70, \\
96.71,96.73,93.90,93.91,93.93,99.60,99.61,99.62 \text {, } \\
99.63,99.69\end{array}$ \\
\hline
\end{tabular}

The key pre-existing and gestational conditions studied were: chronic and gestational DM, chronic and gestational hypertension, obesity, heart disease, and mental health diagnoses. These conditions were defined based on the presence of ICD-9-CM diagnosis or procedure codes in the maternal discharge record and are included in Table 3. DM was defined as GDM or chronic DM. Hypertension was defined as gestational (includes preeclampsia), and chronic/superimposed preeclampsia hypertension. Unspecified hypertension was included in the general hypertension definition ("any") but not in the specific sub-classification. Obesity was defined as BMI $\geq 30 \mathrm{~kg} / \mathrm{m}^{2}$ based on the birth certificate maternal height and pre-pregnancy weight; in cases with missing height or weight, obesity was defined by the presence of ICD-9-CM code 278.xx in the maternal discharge record. CD was identified by ICD-9-CM codes $669.70,669.71$ or procedure codes 74.0x, 74.1x, 74.2x, 74.4x, or 74.99. 
Table 3. Administrative codes used to define maternal pre-existing and gestational health conditions

\begin{tabular}{|c|c|c|}
\hline Health Condition & ICD-9-CM Diagnostic Code $^{*}$ & Code definition \\
\hline \multirow[t]{2}{*}{ Diabetes } & $648.8 \mathrm{x}$ & Gestational diabetes \\
\hline & $250.0 x-250.9 x ; 648.80$ & Chronic diabetes \\
\hline \multirow[t]{3}{*}{ Hypertension } & $642.3 x-642.6 x$ & Gestational hypertension \\
\hline & 401.xx-405.xx; 642.0x-652.2x, 642.7x & Chronic hypertension \\
\hline & $642.9 \mathrm{x}$ & Unspecified hypertension \\
\hline \multirow[t]{14}{*}{ Heart disease } & $648.5 x ; 645 . x x-747 . x x$ & Congenital heart disease \\
\hline & 414.xx, 416.xx, 417.xx, 424.xx, 429.xx & Other heart disease \\
\hline & 410.xx + $\mathrm{POA}^{\#}, 411 . \mathrm{xx}+\mathrm{POA}$ & Acute myocardial infarction (MI) \\
\hline & 413.xx + POA & Angina \\
\hline & 415.xx + POA & Acute pulmonary heart disease \\
\hline & 420.xx+ POA & Acute pericarditis \\
\hline & 421.xx + POA & Acute/subacute pericarditis \\
\hline & 422.xx+ POA & Acute myocarditis \\
\hline & 423.xx + POA & Other pericardial \\
\hline & $425 . x x+$ POA & Cardiomyopathy \\
\hline & 426.xx + POA & Conduction disorders \\
\hline & 427.xx + POA & Dysrhythmias \\
\hline & 428.xx + POA & Heart failure \\
\hline & 35.xx-37.xx; 39.xx & Operations on heart and pericardium (procedure codes) \\
\hline \multirow[t]{7}{*}{ Mental health diagnoses } & 296.0x, 296.2x- 296.8x, 298.0x, 300.4x, 311.xx & Mood disorders \\
\hline & $300.0 x, 300.2 x, 300.3 x, 308.0 x, 309.81$ & Anxiety disorders: \\
\hline & 309.xx & Adjustment disorders \\
\hline & 291.xx, 292.xx, 303.xx-305.xx, 648.3x & Substance use disorders \\
\hline & 295.xx, 297.xx & Psychotic disorders \\
\hline & 293.0x, 293.1x & Cognitive disorders \\
\hline & $307.1 x, 307.50-307.54$ & Eating disorders \\
\hline Obesity & $\begin{array}{l}\text { Body mass index (BMI) } \geq 30 \mathrm{~kg} / \mathrm{m}^{2} \text { (as noted on birth } \\
\text { certificate) or } 278 . \mathrm{xx}\end{array}$ & \\
\hline
\end{tabular}

"International Classification of Diseases, Ninth Revision, Clinical Modification; "Present on admission.

\subsection{Confounders}

Socio-demographic characteristics (i.e., maternal age, race/ethnicity, mother's highest education level, Medicaid insurance, prenatal care [PNC] status), year of delivery, obstetrical conditions (placenta previa, premature rupture of membranes [PROM], postterm pregnancy, cord prolapse with compression, cord entanglement with compression, antepartum bleeding/abuption, isoimmune disease, soft tissue conditions [i.e., disorders of the organs and soft tissue of the pelvis]), fetal conditions (polyhydramnios, oligohydramnios, intrauterine growth restriction [IUGR], excessive fetal growth), intrapartum conditions (fetal distress and dystocia), and other pre-existing conditions (Herpes virus infection, presence of renal or hepatic disease) were also used as controls in all models. PNC status was defined as inadequate, adequate, or adequate plus based on the Adequacy of PNC Index. ${ }^{[24]}$ These characteristics, including race/ethnicity, are known to have a potential effect on severe maternal morbidity and CD (outcomes), and were considered as possible confounders for the effect of maternal conditions on both of these outcomes.

Missing values for maternal race/ethnicity, highest education

Published by Sciedu Press level and PNC index ranged from $1.6 \%$ to $5.1 \%$ of the sample. Given the relatively low rate of missing values, these observations were kept in the analyses by defining 'unknown' as a separate level for these variables.

Other potential control variables that were tested and eliminated due to insignificant differences in their association with the route of delivery and/or severe morbidity were: human immunodeficiency virus (HIV) infection, vasa previa, chorioamnionitis, fetal central nervous system abnormality, and idiopathic hydrops or hemolytic disease due to isoimmunization.

\subsection{Statistical analysis}

The specification of the mediation models and decomposition of the risk associated with the key maternal health conditions was based on the publication by Valeri and VanderWeele. ${ }^{[24]}$ The two pathways for the potential effect associated with each health condition (exposure) on severe maternal morbidity (outcome) are (1) a direct effect, and (2) an indirect effect by modifying the risk of $\mathrm{CD}$ (mediator) that in turn is associated with the risk of severe maternal morbidity (see Figure 1). In our case, all three variables of interest are binary. Of 
concern is that the effects of the maternal health condition and $\mathrm{CD}$ on complications may interact, and this is taken into consideration by using the following models.

The decomposition is based on fitting two multiple logistic regression models:

$$
\begin{gathered}
\ln [p(M) /(1-p(M))]=\beta_{0}+\beta_{1} E+\beta_{2}^{\prime} C \\
\ln [p(Y) /(1-p(Y))]=\theta_{0}+\theta_{1} E+\theta_{2} M+\theta_{3} E M+\theta_{4}^{\prime} C
\end{gathered}
$$

where $\mathrm{Y}$ is the outcome, $\mathrm{M}$ the mediator, $\mathrm{E}$ the exposure and $\mathrm{C}$ is a vector of covariates. The natural direct effect (NDE) and natural indirect effect (NIE) are calculated from the estimated model parameters and are given by

$N D E=\theta_{1}+\theta_{3}\left(\beta_{0}+\beta_{2}^{\prime} C\right) ; N I E=\theta_{2} \beta_{1}+\theta_{3} \beta_{1}$

The NDE expresses how much the risk of severe maternal morbidity would change in the presence versus the absence of the pre-existing or gestational condition of interest, and for each delivery, the measure of risk of $\mathrm{CD}$ is based on other covariates in the absence of the maternal health condition. The NIE expresses how much the risk of severe maternal morbidity would change in the presence of the maternal health condition and considers the risk of CD measured in the presence and in the absence of the maternal health condition. The risk of $\mathrm{CD}$ in the absence of the maternal health condition is referred to as the "natural" CD risk and is used here as a counterfactual construct. The TE) expresses how much the risk of severe maternal morbidity would change overall for a change in the presence versus absence of the maternal health condition (irrespective of CD). The TE is calculated based on the average values for the rest of the model covariates, and for our binary outcome models, the TE equals the product of the NDE and NIE (even in the presence of interactions and non-linearity).

Analyses were performed separately for each of the maternal health conditions, and separate models were constructed for younger versus older women (aged $\geq 35$ years) due to substantial differences in measured and potentially unmeasured characteristics. All variable rates were compared by route of delivery and by severe maternal morbidity status and tested with chi-square tests for categorical variables and two-sided two-sample $t$-test for continuous variables. When estimating the risk associated with each specific pre-existing or gestational condition, all other conditions were entered in the model as controls along with the confounders. Given the large sample used multicollinearity was not a concern; therefore all control variables were retained in all models.

Multiple logistic regression models, as described in equations (1) and (2) above, were fitted to severe maternal morbidity status for each of the pre-existing and gestational conditions: 40 chronic DM, GDM, chronic hypertension, gestational hypertension, obesity, heart disease, and mental health diagnoses using the SAS code provided by Valeri and VanderWeele. ${ }^{[25]}$ The interaction between the pre-existing and gestational conditions and CD was tested for each model and retained if significant. Hosmer and Lemeshow ${ }^{[26]}$ goodness-of-fit test was used to assess adequacy of model fit. Odds ratios (ORs) for natural direct, natural indirect, and total effects are reported with $95 \%$ confidence intervals using the delta method. $P$-values less than .05 were considered statistically significant. Analyses were performed using SAS, version 9.3.

\subsection{Model assumptions}

We determined whether CD functioned as a mediator between pre-existing and gestational conditions and severe maternal morbidity, if any of the following conditions were met after controlling for confounders: 1) variation in maternal conditions significantly accounted for variation in $\mathrm{CD}$; 2) variation in $C D$ significantly accounted for variation in severe maternal morbidity; 3) variation in maternal conditions significantly accounted for variation in severe maternal morbidity; and 4) variation in maternal conditions accounted for less of the variation in severe maternal morbidity when controlling for $\mathrm{CD}$. In order to allow for causal interpretation of the effects, it is necessary to assume that there are no unmeasured confounders in the relationships between (1) the exposure and outcome, (2) the mediator and outcome, (3) the exposure and mediator, and (4) no mediator-outcome confounder that is affected by the exposure. We have included socio-demographic characteristics, year of delivery, obstetrical, fetal and intrapartum conditions, and other pre-existing conditions as potential confounders and conducted separate analyses by age group in an attempt to meet these conditions as best as the data permitted.

Of the four assumptions concerning no unmeasured confounders, assumption (2) above regarding the mediatoroutcome relationship has been considered as the most likely to be violated. ${ }^{[25,26]}$ That is, that there are common causes of $\mathrm{CD}$ and severe maternal morbidity for which we have not adjusted. We estimated the potential bias in the NIE estimates due to this form of unmeasured confounding. To accomplish this, unmediated total effects were obtained from logistic models on each of the outcomes, with the same specification as in the mediated models but ignoring the mediator (CD), and modified NIEs were calculated from dividing these unmediated total effects by the corresponding NDEs from the mediated models. Comparison of the modified NIEs to the original NIEs can assess the potential bias, since the unmediated total effects obtained from the models of exposure on outcome are unconfounded. ${ }^{\text {[27] }}$

ISSN 2377-9306 E-ISSN 2377-9330 
Table 4. Distribution of risk factors by route of delivery and age group among laboring women with nulliparous term singleton vertex (NTSV) gestations

\begin{tabular}{|c|c|c|c|c|c|c|}
\hline \multirow[b]{2}{*}{ Variable } & \multicolumn{3}{|c|}{ Younger women $(<35)$} & \multicolumn{3}{|c|}{ Older women $(\geq 35)$} \\
\hline & Vaginal $(\mathrm{N}=351,528)$ & $\mathrm{CD}^{\# 1}(\mathrm{~N}=104,888)$ & $P$ Value* & Vaginal $(N=28,925)$ & $\mathrm{CD}(\mathrm{N}=17,313)$ & P Value* \\
\hline \multicolumn{7}{|l|}{ Socio-demographic } \\
\hline Age category, n (\%) & & & $<.001$ & & & $<.001$ \\
\hline $0-19$ & $84,281(24.0 \%)$ & $17,367(16.6 \%)$ & & & & \\
\hline $20-24$ & $110,940(31.6 \%)$ & $31,448(30.0 \%)$ & & & & \\
\hline $25-29$ & 91,631 (26.1\%) & $30,476(29.1 \%)$ & & & & \\
\hline $30-34$ & 64,676 (18.4\%) & $25,597(24.4 \%)$ & & & & \\
\hline $35-39$ & & & & 24,282 (83.9\%) & $13,542(78.2 \%)$ & \\
\hline $40-44$ & & & & 4,428 (15.3\%) & $3,469(20.0 \%)$ & \\
\hline $45+$ & & & & $215(0.7 \%)$ & $302(1.7 \%)$ & \\
\hline Age of mother ${ }^{\# 2}$, Mean $\left(S D^{\# 3}\right)$ & $24.0(5.1)$ & $25.1(5.1)$ & $<.001$ & $37.3(2.2)$ & $37.7(2.5)$ & $<.001$ \\
\hline Race/Ethnicity, n (\%) & & & $<.001$ & & & $<.001$ \\
\hline Hispanic & $174,592(49.7 \%)$ & $52,274(49.8 \%)$ & & 5,593 (19.3\%) & 4,053 (23.4\%) & \\
\hline Multiple race & $7,819(2.2 \%)$ & 2,390 (2.3\%) & & $662(2.3 \%)$ & $410(2.4 \%)$ & \\
\hline Black, non-Hispanic & $18,847(5.4 \%)$ & 7,266 (6.9\%) & & $740(2.6 \%)$ & $626(3.6 \%)$ & \\
\hline American Indian & $1,110(0.3 \%)$ & $361(0.3 \%)$ & & $29(0.1 \%)$ & $26(0.2 \%)$ & \\
\hline Asian & $44,190(12.6 \%)$ & 13,333 (12.7\%) & & 7,353 (25.4\%) & 4,330 (25.0\%) & \\
\hline Pacific Islander & $1,347(0.4 \%)$ & $443(0.4 \%)$ & & $76(0.3 \%)$ & $42(0.2 \%)$ & \\
\hline White, non-Hispanic & $97,740(27.8 \%)$ & 26,905 (25.7\%) & & $13,601(47.0 \%)$ & $7,297(42.1 \%)$ & \\
\hline Other & $221(0.1 \%)$ & $71(0.1 \%)$ & & $20(0.1 \%)$ & $12(0.1 \%)$ & \\
\hline Unknown & $5,662(1.6 \%)$ & $1,845(1.8 \%)$ & & $851(2.9 \%)$ & $517(3.0 \%)$ & \\
\hline Highest education level, n (\%) & & & $<.001$ & & & $<.001$ \\
\hline Less than high school & 76,102 (21.6\%) & 20,259 (19.3\%) & & $1,366(4.7 \%)$ & $1,061(6.1 \%)$ & \\
\hline High school & 96,095 (27.3\%) & $28,359(27.0 \%)$ & & $2,541(8.8 \%)$ & $1,838(10.6 \%)$ & \\
\hline College or more & $166,626(47.4 \%)$ & $52,559(50.1 \%)$ & & 23,548 (81.4\%) & $13,550(78.3 \%)$ & \\
\hline Missing/Unknown & $12,705(3.6 \%)$ & 3,711 (3.5\%) & & $1,470(5.1 \%)$ & $864(5.0 \%)$ & \\
\hline MediCaid, n (\%) & $169,083(48.1 \%)$ & 50,293 (47.9\%) & $<.001$ & $3,631(12.6 \%)$ & 2,757 (15.9\%) & $<.001$ \\
\hline Prenatal care index, n (\%) & & & $<.001$ & & & $<.001$ \\
\hline Inadequate & $36,305(10.3 \%)$ & $9,419(9.0 \%)$ & & $1,074(3.7 \%)$ & 709 (4.1\%) & \\
\hline Intermediate & $32,688(9.3 \%)$ & $9,721(9.3 \%)$ & & $2,570(8.9 \%)$ & $1,428(8.2 \%)$ & \\
\hline Adequate & $161,522(45.9 \%)$ & 49,532 (47.2\%) & & $13,293(46.0 \%)$ & 7,976 (46.1\%) & \\
\hline Adequate plus & $108,062(30.7 \%)$ & 32,727 (31.2\%) & & $10,839(37.5 \%)$ & 6,663 (38.5\%) & \\
\hline Missing information & $12,951(3.7 \%)$ & 3,489 (3.3\%) & & 1,149 (4.0\%) & 537 (3.1\%) & \\
\hline Year, n (\%) & & & .008 & & & .330 \\
\hline 2008 & $122,601(34.9 \%)$ & 36,256 (34.6\%) & & 9,833 (34.0\%) & 5,811 (33.6\%) & \\
\hline 2009 & $116,107(33.0 \%)$ & $35,180(33.5 \%)$ & & $9,459(32.7 \%)$ & $5,776(33.4 \%)$ & \\
\hline 2010 & $112,820(32.1 \%)$ & 33,452 (31.9\%) & & $9,633(33.3 \%)$ & $5,726(33.1 \%)$ & \\
\hline \multicolumn{7}{|l|}{ Pre-existing or gestational conditions } \\
\hline $\mathrm{DM}^{\# 4}$ (any), $\mathrm{n}(\%)$ & $14,738(4.2 \%)$ & $7,573(7.2 \%)$ & $<.001$ & 3,029 (10.5\%) & $2428(14.0 \%)$ & $<.001$ \\
\hline DM category, n (\%) & & & $<.001$ & & & $<.001$ \\
\hline None & 336,790 (95.8\%) & 97,315 (92.8\%) & & 25,896 (89.5\%) & $14,885(86.0 \%)$ & \\
\hline Chronic +/- gestational DM & $905(0.3 \%)$ & $1,037(1.0 \%)$ & & $161(0.6 \%)$ & $276(1.6 \%)$ & \\
\hline Gestational DM only & $13,833(3.9 \%)$ & $6,536(6.2 \%)$ & & $2,868(9.9 \%)$ & $2,152(12.4 \%)$ & \\
\hline HTN $^{\# 5}$ (any), n (\%) & $21,062(6.0 \%)$ & $13,085(12.5 \%)$ & $<.001$ & $2,173(7.5 \%)$ & $2,343(13.5 \%)$ & $<.001$ \\
\hline HTN category, n (\%) & & & $<.001$ & & & $<.001$ \\
\hline None & $330,466(94.0 \%)$ & $91,803(87.5 \%)$ & & $26,752(92.5 \%)$ & $14,970(86.5 \%)$ & \\
\hline Chronic/Superimposed HTN & $2,111(0.6 \%)$ & $1,512(1.4 \%)$ & & $543(1.9 \%)$ & $585(3.4 \%)$ & \\
\hline Gestational HTN only & $17,869(5.1 \%)$ & $10,974(10.5 \%)$ & & $1,496(5.2 \%)$ & $1,615(9.3 \%)$ & \\
\hline Unspecified HTN & $1,082(0.3 \%)$ & $599(0.6 \%)$ & & $134(0.5 \%)$ & $143(0.8 \%)$ & \\
\hline Obesity, n (\%) & 41,056 (11.7\%) & $23,064(22.0 \%)$ & $<.001$ & $2,719(9.4 \%)$ & 2,889 (16.7\%) & $<.001$ \\
\hline Heart disease, $\mathrm{n}(\%)$ & $1,219(0.3 \%)$ & $537(0.5 \%)$ & $<.001$ & $212(0.7 \%)$ & $142(0.8 \%)$ & .300 \\
\hline Mental health condition, n (\%) & $8,189(2.3 \%)$ & $2,916(2.8 \%)$ & $<.001$ & $874(3.0 \%)$ & $583(3.4 \%)$ & .039 \\
\hline Renal disease, $\mathrm{n}(\%)$ & $499(0.1 \%)$ & $221(0.2 \%)$ & $<.001$ & $40(0.1 \%)$ & $30(0.2 \%)$ & .350 \\
\hline Liver disease, n (\%) & $191(0.1 \%)$ & $83(0.1 \%)$ & 0.004 & $39(0.1 \%)$ & $34(0.2 \%)$ & .110 \\
\hline Herpes, n (\%) & $4,762(1.4 \%)$ & $1,586(1.5 \%)$ & $<.001$ & $758(2.6 \%)$ & $470(2.7 \%)$ & .540 \\
\hline \multicolumn{7}{|l|}{ Obstetrical conditions } \\
\hline Placenta previa, n (\%) & $738(0.2 \%)$ & $563(0.5 \%)$ & $<.001$ & $109(0.4 \%)$ & $237(1.4 \%)$ & $<.001$ \\
\hline Abruption PROM ${ }^{\# 6}, \mathrm{n}(\%)$ & $840(0.2 \%)$ & $1,127(1.1 \%)$ & $<.001$ & $136(0.5 \%)$ & $237(1.4 \%)$ & $<.001$ \\
\hline PROM, n (\%) & $16,731(4.8 \%)$ & $6,736(6.4 \%)$ & $<.001$ & $2,175(7.5 \%)$ & $1,407(8.1 \%)$ & .018 \\
\hline Postterm, n (\%) & $66,616(19.0 \%)$ & $31,549(30.1 \%)$ & $<.001$ & $6,149(21.3 \%)$ & $5,245(30.3 \%)$ & $<.001$ \\
\hline Cord prolapse with compression, n (\%) & $198(0.1 \%)$ & $529(0.5 \%)$ & $<.001$ & $17(0.1 \%)$ & $73(0.4 \%)$ & $<.001$ \\
\hline Cord entanglement + compression, $\mathrm{n}(\%)$ & $21,762(6.2 \%)$ & $5,754(5.5 \%)$ & $<.001$ & 2,064 (7.1\%) & $965(5.6 \%)$ & $<.001$ \\
\hline Antepartum bleed, n (\%) & $1,670(0.5 \%)$ & $1,725(1.6 \%)$ & $<.001$ & $264(0.9 \%)$ & $482(2.8 \%)$ & $<.001$ \\
\hline Isoimmune disease, $\mathrm{n}(\%)$ & $5,566(1.6 \%)$ & $1,504(1.4 \%)$ & $<.001$ & $523(1.8 \%)$ & $263(1.5 \%)$ & .020 \\
\hline Soft tissue condition, $\mathrm{n}(\%)$ & $129,032(36.7 \%)$ & $48,245(46.0 \%)$ & $<.001$ & $13,383(46.3 \%)$ & $9,870(57.0 \%)$ & $<.001$ \\
\hline \multicolumn{7}{|l|}{ Fetal conditions } \\
\hline Polyhydramnios, n (\%) & $521(0.1 \%)$ & $606(0.6 \%)$ & $<.001$ & $77(0.3 \%)$ & $157(0.9 \%)$ & $<.001$ \\
\hline Oligohydramnios, n (\%) & $10,000(2.8 \%)$ & $5,756(5.5 \%)$ & $<.001$ & $1,016(3.5 \%)$ & $1,060(6.1 \%)$ & $<.001$ \\
\hline $\mathrm{IUGR}^{\# 7}, \mathrm{n}(\%)$ & $4,537(1.3 \%)$ & $1,814(1.7 \%)$ & $<.001$ & $433(1.5 \%)$ & $326(1.9 \%)$ & .002 \\
\hline Excessive fetal growth, $\mathrm{n}(\%)$ & $3,042(0.9 \%)$ & 5,599 (5.3\%) & $<.001$ & $320(1.1 \%)$ & 896 (5.2\%) & $<.001$ \\
\hline \multicolumn{7}{|l|}{ Intra-partum conditions } \\
\hline Fetal distress, n (\%) & $56,785(16.2 \%)$ & $47,723(45.5 \%)$ & $<.001$ & $5,899(20.4 \%)$ & $8,023(46.3 \%)$ & $<.001$ \\
\hline Dystocia, n (\%) & $24,362(6.9 \%)$ & $77,411(73.8 \%)$ & $<.001$ & $3,290(11.4 \%)$ & $12,403(71.6 \%)$ & $<.001$ \\
\hline
\end{tabular}




\section{Results}

\subsection{Descriptive summaries}

The dataset included 529,645 California NTSV deliveries that occurred between 2008-2010 and were linked to the birth certificate. Of these, $26,936 \mathrm{CD}$ with no codes to indicate labor and 55 deliveries missing maternal age were excluded. The remaining 502,654 deliveries (94.95\%) were included in this analysis. The overall maternal mean age was 25.5 (6.2) years with a range of 11-54 years; most deliveries, 456,416 (90.8\%), were to younger mothers, with the following racial/ethnic distribution: $47.1 \%$ of Hispanic origin, 29.0\% White, $13.8 \%$ Asian, 5.5\% African-American, and the remainder were of other or unknown race/ethnicity. Medicaid was the principal insurance payer for $44.9 \%$ of women. The most prevalent pre-existing conditions were obesity $(13.9 \%)$, hypertension $(7.7 \%$ of which $6.4 \%$ was classified as gestational hypertension) and DM (5.5\% of which $5.1 \%$ was GDM).

Table 4 presents the distribution of risk factors for women by delivery route and maternal age group. There were 122,201 (24.3\%) CD reported. Older women were more likely to undergo CD compared to younger women (37.4\% vs. 23.0\%). For both younger and older mothers, the presence of most obstetrical, fetal and intrapartum conditions listed was associated with a $\mathrm{CD}(p<.01)$. With respect to the key pre-existing health conditions, the prevalence of DM, hypertension, and obesity was specifically noted to be higher among older women and women undergoing CD.

Women experienced severe maternal morbidity in $1.7 \%$ of deliveries; this proportion was $1.6 \%$ for younger and $2.2 \%$ for older women. Table 5 presents the distribution of risk factors for women with and without severe maternal morbidity by maternal age group. Rates of $\mathrm{CD}$ associated with severe maternal morbidity were higher in both younger $(44.7 \% \mathrm{vs}$. $22.6 \%)$ and older women $(53.4 \%$ vs. $37.1 \%)(p<.001)$. The presence of most maternal health, fetal, and intrapartum conditions studied was also associated with severe maternal morbidity for both younger and older women $(p<.01)$.

Table 5. Distribution of risk factors by presence of severe maternal complications and age group among laboring women with nulliparous term singleton vertex (NTSV) gestations

\begin{tabular}{|c|c|c|c|c|c|c|}
\hline \multirow[b]{2}{*}{ Variable } & \multicolumn{3}{|c|}{ Younger women $(<35$ years) } & \multicolumn{3}{|c|}{ Older women ( $\geq 35$ years) } \\
\hline & $\begin{array}{l}\text { No Severe Complications } \\
(\mathrm{N}=\mathbf{4 4 8 , 9 2 7 )}\end{array}$ & $\begin{array}{l}\text { Severe Complications } \\
(N=7,489)\end{array}$ & $P$ Value* & $\begin{array}{l}\text { No Severe Complications } \\
(\mathrm{N}=\mathbf{4 5 , 2 3 1 )}\end{array}$ & $\begin{array}{l}\text { Severe Complications } \\
(\mathrm{N}=\mathbf{1 , 0 0 7 )}\end{array}$ & P Value* \\
\hline \multicolumn{7}{|l|}{ Cesarean delivery } \\
\hline $\mathrm{CD}^{\# 1}, \mathrm{n}(\%)$ & $101,541(22.6 \%)$ & 3,347 (44.7\%) & $<.001$ & $16,775(37.1 \%)$ & $538(53.4 \%)$ & $<.001$ \\
\hline \multicolumn{7}{|l|}{ Socio-demographic } \\
\hline Age category, n (\%) & & & .031 & & & .120 \\
\hline $20-24$ & $140,091(31.2 \%)$ & 2,297 (30.7\%) & & & & \\
\hline $25-29$ & $120,184(26.8 \%)$ & $1,923(25.7 \%)$ & & & & \\
\hline $30-34$ & $88,721(19.8 \%)$ & 1,552 (20.7\%) & & & & \\
\hline $35-39$ & & & & 37,018 (81.8\%) & $806(80.0 \%)$ & \\
\hline $40-44$ & & & & 7,713 (17.1\%) & $184(18.3 \%)$ & \\
\hline $45+$ & & & & $500(1.1 \%)$ & $17(1.7 \%)$ & \\
\hline Race/Ethnicity, n (\%) & & & $<.001$ & & & $<.001$ \\
\hline Hispanic & 222,878 (49.6\%) & 3,988 (53.3\%) & & $9,423(20.8 \%)$ & $223(22.1 \%)$ & \\
\hline Multiple race & $10,068(2.2 \%)$ & $141(1.9 \%)$ & & $1,048(2.3 \%)$ & $24(2.4 \%)$ & \\
\hline Black, non-Hispanic & $25,644(5.7 \%)$ & $469(6.3 \%)$ & & $1,329(2.9 \%)$ & $37(3.7 \%)$ & \\
\hline American Indian & $1,451(0.3 \%)$ & $20(0.3 \%)$ & & $50(0.1 \%)$ & $5(0.5 \%)$ & \\
\hline Asian & $56,459(12.6 \%)$ & $1,064(14.2 \%)$ & & $11,386(25.2 \%)$ & $297(29.5 \%)$ & \\
\hline Pacific Islander & $1,756(0.4 \%)$ & $34(0.5 \%)$ & & $116(0.3 \%)$ & $2(0.2 \%)$ & \\
\hline White, non-Hispanic & $123,000(27.4 \%)$ & $1,645(22.0 \%)$ & & $20,509(45.3 \%)$ & $389(38.6 \%)$ & \\
\hline Other & $287(0.1 \%)$ & $5(0.1 \%)$ & & $31(0.1 \%)$ & $1(0.1 \%)$ & \\
\hline Unknown & 7,384 (1.6\%) & $123(1.6 \%)$ & & $1,339(3.0 \%)$ & $29(2.9 \%)$ & \\
\hline Highest education level, n (\%) & & & $<.001$ & & & .200 \\
\hline Less than high school & $94,547(21.1 \%)$ & $1,814(24.2 \%)$ & & $2,373(5.2 \%)$ & $54(5.4 \%)$ & \\
\hline High school & $122,478(27.3 \%)$ & $1,976(26.4 \%)$ & & $4,264(9.4 \%)$ & $115(11.4 \%)$ & \\
\hline Medicaid insurance, n (\%) & $215,656(48.0 \%)$ & $3,720(49.7 \%)$ & $<.001$ & 6,239 (13.8\%) & $149(14.8 \%)$ & .160 \\
\hline
\end{tabular}


Table 5. (continued.)

\begin{tabular}{|c|c|c|c|c|c|c|}
\hline \multirow[b]{2}{*}{ Variable } & \multicolumn{3}{|c|}{ Younger women $(<35)$} & \multicolumn{3}{|c|}{ Older women $(\geqslant 35)$} \\
\hline & $\begin{array}{l}\text { No Severe Complications } \\
(\mathrm{N}=448,927)\end{array}$ & $\begin{array}{l}\text { Severe Complications } \\
(\mathrm{N}=7,489)\end{array}$ & $P$ Value* & $\begin{array}{l}\text { No Severe Complications } \\
(\mathrm{N}=45,231)\end{array}$ & $\begin{array}{l}\text { Severe Complications } \\
(\mathrm{N}=\mathbf{1 , 0 0 7 )}\end{array}$ & $P$ Value* \\
\hline Prenatal care index, n (\%) & & & $<.001$ & & & .003 \\
\hline Intermediate & 41,632 (9.3\%) & 777 (10.4\%) & & $3,880(8.6 \%)$ & $118(11.7 \%)$ & \\
\hline Adequate & $207,776(46.3 \%)$ & 3,278 (43.8\%) & & $20,837(46.1 \%)$ & $432(42.9 \%)$ & \\
\hline Adequate plus & $138,468(30.8 \%)$ & 2,321 (31.0\%) & & $17,133(37.9 \%)$ & 369 (36.6\%) & \\
\hline Year, n (\%) & & & $<.001$ & & & .570 \\
\hline 2008 & $156,426(34.8 \%)$ & 2,431 (32.5\%) & & $15,319(33.9 \%)$ & 325 (32.3\%) & \\
\hline 2009 & $148,701(33.1 \%)$ & 2,586 (34.5\%) & & 14,897 (32.9\%) & $338(33.6 \%)$ & \\
\hline 2010 & $143,800(32.0 \%)$ & $2,472(33.0 \%)$ & & $15,015(33.2 \%)$ & $344(34.2 \%)$ & \\
\hline \multicolumn{7}{|l|}{$\begin{array}{l}\text { Pre-existing or pregnancy-related } \\
\text { conditions }\end{array}$} \\
\hline $\mathrm{DM}^{\# 4}$ (any), n (\%) & $21,869(4.9 \%)$ & $442(5.9 \%)$ & $<.001$ & $5,309(11.7 \%)$ & $148(14.7 \%)$ & .004 \\
\hline DM category, n (\%) & & & $<.001$ & & & .015 \\
\hline Chronic +/- gestational DM & $1,890(0.4 \%)$ & $52(0.7 \%)$ & & $426(0.9 \%)$ & $11(1.1 \%)$ & \\
\hline Gestational DM only & $19,979(4.5 \%)$ & 390 (5.2\%) & & 4,883 (10.8\%) & $137(13.6 \%)$ & \\
\hline $\mathrm{HTN}^{\# 5}$ (any), n (\%) & $32,831(7.3 \%)$ & $1,316(17.6 \%)$ & $<.001$ & 4,332 (9.6\%) & $184(18.3 \%)$ & $<.001$ \\
\hline HTN category, n (\%) & & & $<.001$ & & & $<.001$ \\
\hline None & 416,096 (92.7\%) & 6,173 (82.4\%) & & 40,899 (90.4\%) & $823(81.7 \%)$ & \\
\hline Chronic/Superimposed HTN & $3,527(0.8 \%)$ & $96(1.3 \%)$ & & $1,089(2.4 \%)$ & $39(3.9 \%)$ & \\
\hline Gestational HTN only & 27,669 (6.2\%) & $1,174(15.7 \%)$ & & $2,980(6.6 \%)$ & $131(13.0 \%)$ & \\
\hline Unspecified HTN & $1,635(0.4 \%)$ & $46(0.6 \%)$ & & $263(0.6 \%)$ & $14(1.4 \%)$ & \\
\hline Obesity, n (\%) & $63,040(14.0 \%)$ & $1,080(14.4 \%)$ & .35 & $5,478(12.1 \%)$ & $130(12.9 \%)$ & .440 \\
\hline Heart disease, $\mathrm{n}(\%)$ & $1,531(0.3 \%)$ & $225(3.0 \%)$ & $<.001$ & $310(0.7 \%)$ & $44(4.4 \%)$ & $<.001$ \\
\hline Mental health diagnosis, n (\%) & $10,792(2.4 \%)$ & $313(4.2 \%)$ & $<.001$ & $1,407(3.1 \%)$ & $50(5.0 \%)$ & $<.001$ \\
\hline Renal disease, $\mathrm{n}(\%)$ & $686(0.2 \%)$ & $34(0.5 \%)$ & $<.001$ & $65(0.1 \%)$ & $5(0.5 \%)$ & .004 \\
\hline Liver disease, $\mathrm{n}(\%)$ & $253(0.1 \%)$ & $21(0.3 \%)$ & $<.001$ & $68(0.2 \%)$ & $5(0.5 \%)$ & .006 \\
\hline Herpes, n (\%) & 6,209 (1.4\%) & 139 (1.9\%) & $<.001$ & $1,193(2.6 \%)$ & $35(3.5 \%)$ & .100 \\
\hline Abruption $\mathrm{PROM}^{\# 6}, \mathrm{n}(\%)$ & $1,854(0.4 \%)$ & $113(1.5 \%)$ & $<.001$ & $351(0.8 \%)$ & $22(2.2 \%)$ & $<.001$ \\
\hline PROM, n (\%) & $23,008(5.1 \%)$ & 459 (6.1\%) & $<.001$ & $3,496(7.7 \%)$ & $86(8.5 \%)$ & .340 \\
\hline Postterm, n (\%) & $96,214(21.4 \%)$ & $1,951(26.1 \%)$ & $<.001$ & $11,134(24.6 \%)$ & $260(25.8 \%)$ & .380 \\
\hline Cord prolapse with compression, n (\%) & $704(0.2 \%)$ & $23(0.3 \%)$ & 0.001 & $85(0.2 \%)$ & $5(0.5 \%)$ & .028 \\
\hline Cord entanglement + compression, n (\%) & $27,136(6.0 \%)$ & $380(5.1 \%)$ & $<.001$ & $2,963(6.6 \%)$ & $66(6.6 \%)$ & 1.000 \\
\hline Antepartum bleed, n (\%) & $3,218(0.7 \%)$ & $177(2.4 \%)$ & $<.001$ & $699(1.5 \%)$ & $47(4.7 \%)$ & $<.001$ \\
\hline Isoimmune disease, $\mathrm{n}(\%)$ & $6,950(1.5 \%)$ & $120(1.6 \%)$ & .71 & $776(1.7 \%)$ & $10(1.0 \%)$ & .080 \\
\hline Soft tissue condition, n (\%) & $174,006(38.8 \%)$ & $3,271(43.7 \%)$ & $<.001$ & $22,685(50.2 \%)$ & $568(56.4 \%)$ & $<.001$ \\
\hline \multicolumn{7}{|l|}{ Fetal conditions } \\
\hline Polyhydramnios, n (\%) & $1,078(0.2 \%)$ & $49(0.7 \%)$ & $<.001$ & $225(0.5 \%)$ & $9(0.9 \%)$ & .080 \\
\hline Oligohydramnios, n (\%) & $15,456(3.4 \%)$ & $300(4.0 \%)$ & 0.008 & $2,031(4.5 \%)$ & $45(4.5 \%)$ & .970 \\
\hline $\mathrm{IUGR}^{\# 7}, \mathrm{n}(\%)$ & $6,262(1.4 \%)$ & $89(1.2 \%)$ & .13 & $738(1.6 \%)$ & $21(2.1 \%)$ & .260 \\
\hline Excessive fetal growth, n (\%) & 8,396 (1.9\%) & $245(3.3 \%)$ & $<.001$ & $1,177(2.6 \%)$ & $39(3.9 \%)$ & .013 \\
\hline \multicolumn{7}{|l|}{ Intra-partum conditions } \\
\hline Fetal distress, n (\%) & $102,188(22.8 \%)$ & $2,320(31.0 \%)$ & $<.001$ & $13,551(30.0 \%)$ & $371(36.8 \%)$ & $<.001$ \\
\hline Dystocia, n (\%) & $98,795(22.0 \%)$ & 2,978 (39.8\%) & $<.001$ & 15,265 (33.7\%) & $428(42.5 \%)$ & $<.001$ \\
\hline
\end{tabular}

${ }^{{ }^{11} \mathrm{CD}}=$ Cesarean delivery; ${ }^{* 2}$ Women with missing age $(\mathrm{n}=55)$ excluded; ${ }^{* 3} \mathrm{SD}=$ Standard deviation; ${ }^{* 4} \mathrm{DM}=$ Diabetes mellitus; ${ }^{* 5} \mathrm{HTN}=$ Hypertension; ${ }^{*}$ PROM $=$ Premature rupture of membranes; ${ }^{* 7} \mathrm{IUGR}=$ Intrauterine growth restriction; *Chi-square and two-sided two-sample $t$ tests for categorical and continuous variables, respectively.

\subsection{Modeling results}

Heart disease and hypertension had the highest total effects on severe maternal morbidity in both age groups (see Table $6)$. For younger and older women, the adjusted odds ratios $(95 \% \mathrm{CI})$ for heart disease were $8.38(7.16,9.81)$ and 6.48 $(4.65,9.03)$, respectively. For any hypertension, the total effects were $2.77(2.59,2.97)$ and $2.11(1.79,2.52)$.

Decomposition of these total effects showed that most of the impact of these comorbid conditions on severe mater- nal morbidity was direct, and not through the increased risk of CD. The direct effects of heart disease for younger and older women were $7.97(6.79,9.36)$ and $6.57(4.73,9.14)$, respectively. In younger women the indirect risk of severe maternal morbidity due to heart disease was increased by $5 \%$ (indirect effect OR $1.05,1.01,1.10$ ) as a result of the increased risk of $\mathrm{CD}$. There was no significant indirect effect in older women. The direct effects of any hypertension for younger and older women were $2.67(2.47,2.88)$ and $2.00(1.68,2.37)$, respectively. In younger women, the in- 
direct risk of severe maternal morbidity from hypertension was increased by 4\% (indirect effect OR 1.04 [1.03, 1.06]) and by $6 \%$ (indirect effect OR 1.06 [1.04, 1.09]) in older women. Separate examination of chronic/superimposed and gestational hypertension showed similar risk decomposition and that the direct effect from gestational hypertension was higher: the OR was 2.84 in younger and 2.09 in older women compared to the chronic/superimposed hypertension OR of 1.59 and 1.64 in younger and older age groups, respectively.

Table 6. Natural direct effect (NDE), natural indirect effect (NIE) and total effect (TE) of pre-existing and gestational conditions (comorbid conditions) on severe maternal morbidity mediated by cesarean delivery (CD) among laboring women with nulliparous term singleton vertex (NTSV) gestations ${ }^{\# 1}$

\begin{tabular}{|c|c|c|c|c|c|c|c|c|c|c|c|c|}
\hline & \multicolumn{6}{|c|}{ Younger women $(<35$ years $)$} & \multicolumn{6}{|c|}{ Older women ( $\geq 35$ years) } \\
\hline & \multicolumn{2}{|l|}{ NDE } & \multicolumn{2}{|l|}{ NIE } & \multicolumn{2}{|l|}{ TE } & \multicolumn{2}{|l|}{ NDE } & \multicolumn{2}{|l|}{ NIE } & \multicolumn{2}{|l|}{ TE } \\
\hline & OR & $95 \%$ CI & OR & $95 \%$ CI & OR & $95 \%$ CI & OR & $95 \%$ CI & OR & $95 \%$ CI & OR & $95 \%$ CI \\
\hline \multirow{3}{*}{ Any diabetes } & \multicolumn{6}{|c|}{ Comorbid cases $\mathrm{n}=22,311(4.9 \%)^{\# 3, \# 4}$} & \multicolumn{6}{|c|}{ Comorbid cases $\mathrm{n}=5,457(11.8 \%)^{\# 3, \# 4}$} \\
\hline & 0.981 & $0.884-1.090$ & 1.030 & $1.024-1.037$ & 1.011 & $0.910-1.123$ & 1.093 & $0.894-1.338$ & 1.001 & $0.990-1.012$ & 1.094 & $0.894-1.339$ \\
\hline & \multicolumn{6}{|c|}{ Any diabetes was not significant in the outcome model } & \multicolumn{6}{|c|}{ Any diabetes was not significant in the outcome and CD models } \\
\hline \multirow{3}{*}{$\begin{array}{l}\text { Chronic } \\
\text { diabetes ( } \pm \\
\text { gestational } \\
\text { diabetes) }\end{array}$} & \multicolumn{6}{|c|}{ Comorbid cases $n=1,942(0.4 \%)^{\# 3, \# 4}$} & \multicolumn{6}{|c|}{ Comorbid cases $n=437(0.9 \%)^{\# 3, \# 4}$} \\
\hline & 0.995 & $0.749-1.322$ & 1.111 & $1.086-1.137$ & 1.106 & $0.832-1.470$ & 0.792 & $0.424-1.479$ & 1.061 & $1.020-1.103$ & 0.841 & $0.450-1.571$ \\
\hline & Chroni & tes was not sig & icant in $\mathrm{t}$ & outcome mode & & & Chroni & abetes was not & nnificant & he outcome $\mathrm{m}$ & & \\
\hline \multirow{3}{*}{$\begin{array}{l}\text { Gestational } \\
\text { diabetes only }\end{array}$} & \multicolumn{6}{|c|}{ Comorbid cases $\mathrm{n}=20,369(4.5 \%)^{\# 2, \# 4}$} & \multicolumn{6}{|c|}{ Comorbid cases $\mathrm{n}=5,020(10.9 \%)^{\# 2, \# 4}$} \\
\hline & 0.907 & $0.794-1.037$ & 1.033 & $1.021-1.046$ & 0.937 & $0.824-1.066$ & 1.124 & $0.915-1.381$ & 0.996 & $0.985-1.007$ & 1.119 & $0.911-1.376$ \\
\hline & Gestati & labetes was no & gnificant & the outcome $m$ & & & Gestati & diabetes was & signific & in the outcome & $\mathrm{d}$ CD m & \\
\hline $\begin{array}{l}\text { Any } \\
\text { hypertension }\end{array}$ & \multicolumn{6}{|c|}{ Comorbid cases $n=34,147(7.5 \%)^{\# 2}$} & \multicolumn{6}{|c|}{ Comorbid cases $n=4,516(9.8 \%)^{\# 3}$} \\
\hline \multirow{2}{*}{$\begin{array}{l}\text { Chronic/ } \\
\text { Superimposed } \\
\text { hypertension }\end{array}$} & \multicolumn{6}{|c|}{ Comorbid cases $n=3,623(0.8 \%)^{\# 3}$} & \multicolumn{6}{|c|}{ Comorbid cases $n=1,128(2.4 \%)^{\# 3}$} \\
\hline & 1.587 & $1.285-1.958$ & 1.067 & $1.051-1.083$ & 1.693 & $1.371-2.090$ & 1.644 & $1.168-2.313$ & 1.055 & $1.026-1.084$ & 1.734 & $1.231-2.441$ \\
\hline \multirow{2}{*}{$\begin{array}{l}\text { Gestational } \\
\text { hypertension } \\
\text { only }\end{array}$} & \multicolumn{6}{|c|}{ Comorbid cases $n=28,843(6.3 \%)^{\# 2}$} & \multicolumn{6}{|c|}{ Comorbid cases $n=3,111(6.7 \%)^{\# 3}$} \\
\hline & 2.842 & $2.627-3.074$ & 1.038 & $1.023-1.053$ & 2.949 & $2.743-3.170$ & 2.090 & $1.721-2.537$ & 1.068 & $1.041-1.095$ & 2.231 & $1.837-2.710$ \\
\hline \multirow{3}{*}{ Obesity } & Comor & es $n=64,120$ & $.0 \%)^{\# 3}$ & & & & Comor & cases $n=5,60$ & $2.1 \%)^{\# 3}$ & & & \\
\hline & 0.778 & $0.726-0.833$ & 0.966 & $0.962-0.969$ & 0.751 & $0.701-0.804$ & 0.857 & $0.702-1.047$ & 0.939 & $0.921-0.958$ & 0.805 & $0.658-0.985$ \\
\hline & & & & & & & Obesit & Is not significa & $n$ the ou & ne model & & \\
\hline & Comor & $\mathrm{es}=1,756$ & $\%)^{\# 2}$ & & & & Comor & cases $n=354$ & $\%)^{\# 3, \# 4}$ & & & \\
\hline Heart disease & 7.972 & 6.795-9.362 & 1.051 & $1.009-1.097$ & 8.379 & 7.164-9.805 & 6.570 & $4.725-9.136$ & 0.987 & 0.956-1.019 & 6.483 & $4.655-9.029$ \\
\hline & & & & & & & Heart c & se was not sig & cant in $t$ & CD model & & \\
\hline & Comor & $\mathrm{es}=11,105$ & $4 \%)^{\# 3, \# 4}$ & & & & Comor & cases $n=1,45$ & $.2 \%)^{\# 3}$ & & & \\
\hline Mental health & 1.581 & $1.400-1.785$ & 0.998 & $0.992-1.003$ & 1.577 & $1.397-1.781$ & 1.433 & $1.058-1.940$ & 0.981 & 0.963-0.999 & 1.405 & $1.038-1.904$ \\
\hline
\end{tabular}

"I Outcome and mediator logistic regression models adjusted for: Race/ethnicity, mother's education level, medicaid insurance, PNC index, year of delivery, placenta previa, abruption with premature rupture of membranes (PROM), PROM, postterm, cord prolapse with compression, cord entanglement with compression, antepartum bleed, isoimmune disease, soft tissue condition, polyhydramnios, oligohydramnios, intrauterine growth restriction, excessive fetal growth, renal disease, liver disease, herpes, fetal distress, dystocia and comorbid conditions other than the specific one under consideration. Interaction between comorbid condition of interest (exposure) and cesarean delivery (CD) (mediator) tested for each model and included in outcome logistic regression if significant.

${ }^{22}$ Significant interaction between comorbid condition of interest (exposure) and CD (mediator) included in the outcome logistic regression model.

${ }^{* 3}$ Insignificant interaction between comorbid condition of interest (exposure) and CD (mediator) not included in the outcome logistic regression model.

${ }^{* 4}$ Conditions not met due to insignificance of the adjusted effect of maternal condition (exposure) and/or $\mathrm{CD}$ (mediator). Specifics indicated in footnote under model results for each maternal condition

The total effects of any DM, chronic, and gestational DM on severe maternal morbidity were insignificant in both age groups. However, for the younger women, there were significant indirect effects of $1.03(1.03,1.04)$ for any DM, $1.11(1.09,1.14)$ for chronic DM, and $1.03(1.02,1.05)$ for GDM as a result of the increased risk of an CD. For older women, only a significant indirect effect of $1.06(1.02,1.10)$ in women with chronic DM was observed.

Obesity had a total effect of $0.75(0.70,0.80)$ for younger women, driven primarily by a direct effect of $0.78(0.73$, 0.83). Similar results were observed in older women. For both younger and older women, there was a significant indirect effect slightly below " 1 ".

Mental health diagnoses had a total effect on severe maternal morbidity of $1.58(1.40,1.79)$ and $1.43(1.06,1.94)$ in younger and older women, respectively. The indirect effects were close to " 1 " for both age groups and insignificant for the younger women. Therefore, almost all the increased risk of severe maternal morbidity appeared attributable directly to the mental health diagnoses.

Assessment of potential bias in the NIE estimates due to violation of the assumption of no unmeasured confounding 
of the exposure-outcome relationship showed mostly small estimate biases of less than $5 \%$ absolute change, with the exception of $10 \%, 9 \%$, and $7 \%$ change in younger women's gestational hypertension, any hypertension, and gestational DM, respectively.

\section{Discussion}

This study took a mediation approach to evaluate the impact of key pre-existing and gestational conditions on severe maternal morbidity and the risk mediated through an emergent CD. We focused on laboring, NTSV women to obtain a more homogeneous sample and built separate models for each health condition and for younger versus older women.

Most studies that address the question of the total effect of pre-existing conditions on severe maternal morbidity consider composite pre-existing condition measures ${ }^{[6,8,31,32]}$ with varying degree of adjustment for confounders. Definitions of the pre-existing condition composite also vary, but all include diabetes and hypertension as the conditions with the highest prevalence, heart disease as the condition with highest risk, and some include mental disease. ${ }^{[8,32]} \mathrm{In}$ a Washington State population-based study, Gray et al. ${ }^{[8]}$ reported an OR of 2.1-fold increased risk of severe maternal morbidity for women with at least one pre-existing condition, with older women at higher risk of severe maternal morbidity. Two other large population-based studies from Australia/Ireland ${ }^{[7]}$ and from Canada ${ }^{[6]}$ found ORs of 2.6 and 5.8, respectively. Goffman et al. ${ }^{[31]}$ found an OR of 2.7 in a matched case-control US study on chronic conditions. In another recent population-based study from Australia, Lindquist et al. ${ }^{[32]}$ found an OR of 1.4. Collectively, these ORs are comparable to our findings in a broad sense, both in terms of direction and magnitude of effect.

As in the current study, some authors separately examined specific pre-existing conditions. Grobman et al. ${ }^{[5]}$ examined the total effect of specific pre-existing conditions in a large study of deliveries in the US. These included diabetes, hypertension and antenatal anticoagulant use as an indication of heart disease; ORs were 1.6 (borderline significant) for chronic and 2.1 for gestational diabetes, 3.4 for hypertension and 5.2 for anticoagulant use, adjusting for socio-demographic, parity, gestational age and obstetrical complication factors. A prospective Canadian study found $13 \%$ severe maternal morbidity or mortality in women with pre-existing heart disease, ${ }^{[33]}$ which is an 8 to 10 - fold higher risk than that found in the general delivery population. Palasmaa et al.${ }^{[17]}$ studied severe maternal morbidity in all Finnish singleton deliveries with labor (i.e., attempted vaginal delivery) between 2007-2011 and found adjusted ORs of 2.0 for pre-eclampsia and non-significant effects for
DM. Compared to our non-significant total effects for diabetes, "any" hypertension effects of 2.7 and 2.0 and heart disease effects of 8.0 and 6.6 for older and younger women, respectively, there is considerable variation in these effect sizes. The OR estimates of Palasmaa et al. ${ }^{[17]}$ study are closer to our findings, and this is probably due to the greater similarity between the studies (i.e., specifically focusing on singleton deliveries undergoing labor). It is also possible that the elevated ORs associated with chronic and gestational hypertension may be due to the inclusion of women who underwent cesarean without labor; such non-laboring women are generally sicker and at increased risk for experiencing severe maternal morbidity. This population was not captured in our model and their exclusion may explain the decreased the magnitude of our effect sizes for these conditions. Still, the substantially largest effect of heart disease, and the larger effect of hypertension compared to diabetes was evident in all studies.

With regard to obesity, two studies found a moderate (OR $=1.2$ ) increased risk of severe maternal morbidity ${ }^{[8,17]}$ and another study found a non-significant effect. ${ }^{[31]}$ All defined obesity as BMI $\geq 30 \mathrm{~kg} / \mathrm{m}^{2}$, but there were many variations in study design (e.g., use of clinical registries or case-control methods) and definitions of severe maternal morbidity, with some studies including wound infections or separations, and longer postpartum follow up (i.e., periods ranged from 6 weeks to 1 year for maternal mortality). In contrast to other studies, we found a seemingly "protective" effect of obesity. Possible reasons for the reversal in the obesity effect may be that our results were limited to events reported to happen within the hospital during the delivery admission that were recorded in an administrative database. Further, we limited the population of interest to NTSV laboring women, stratifying by age group and adjusting for a comprehensive set of pre-existing, obstetrical, fetal, and intra-partum conditions. Further research is needed to confirm the direction and magnitude of impact of obesity on a standardized definition of severe maternal morbidity. We are not aware of studies that examined the separate effect of mental health on severe maternal morbidity. Our total effect showed moderate increased risks of OR $=1.6$ and 1.4 for younger and older women, respectively.

While our age-stratified analyses generally found similar or lower effects for older women, other studies that adjusted for age generally found a non-significant age $\geq 35$ effect $^{[7,17]}$ or a higher risk (ORs from 1.06 to 1.7) of severe maternal morbidity for older women. ${ }^{[5,8,30]}$ However, these studies did not consider potential interactions of age with the risk factors of interest and did not consider non-linear relationships with age. For example, why were younger women with 
hypertension and heart disease found to be at higher risk than older women? It may be that they have more severe disease, but disease severity could not be established with ICD-9-CM codes alone. Furthermore, younger women with heart disease in pregnancy may be receiving the diagnosis and treatment for the first time, especially when considering that half of all cardiac disease in pregnancy is congenital. ${ }^{[34]}$

Our attempt at decomposing the effect of several pre-existing and gestational maternal conditions is an original contribution to the literature that estimates the degree to which the severe maternal morbidity risk for NTSV laboring women is directly attributable to the conditions and how much of that risk is mediated by increasing the risk of CD. We generally found low indirect effects for the pre-existing and gestational conditions ranging from $0.94-1.11(-6 \%$ to $11 \%)$ for all models, indicating that, for these women, the presence of the condition was the main driver for the higher severe maternal morbidity risk; exceptions were found for DM and obesity. The quantification of the direct and indirect risks for severe maternal morbidity will require further exploration to better understand the clinical implication of these findings. Explanations for these findings remain speculative because they have not been well-examined in the obstetrical literature.

The strengths of this study include the use of a large population-based sample and a linked dataset that allowed for the inclusion of multiple covariates potentially related to the maternal outcome. The definition of the study population (i.e., laboring women with NTSV gestations), and the stratification by age, facilitated the interpretation of the results by removing potentially strong confounders and interactions. Limitations of this study include the use of administrative data, which rely on ICD-9-CM codes that may not distinguish the severity or acuity of the condition, and although highly specific, are likely to be under-reported. Although this particular database undergoes routine validity checks, and has been found to be reliable regarding method of delivery, routine quality checks of the key maternal clinical conditions evaluated and the severe maternal morbidity outcomes are not done. The prevalence of the conditions studied in this investigation likely reflects a minimum baseline for the state of California. We also note that the findings are limited to California, although with approximately 500,000 births each

\section{REFERENCES}

[1] American College of Obstetricians and Gynecologists (ACOG). Levels of maternal care. Obstetric Care Consensus No. 2. Obstetrics and Gynecology. 2015; 125(2): 502-515. PMid:25611640 http: //dx.doi.org/10.1097/01.AOG.0000460770.99574.9f year, this represents $12.6 \%$ of all births in the United States (US), more than any other US state. ${ }^{[35]}$

The benefits of working with a large sample come with the difficulty in interpreting statistical significance, as even small differences are statistically significant with large samples. Therefore, we emphasized the results with the largest effects that are likely to also be clinically meaningful.

Several assumptions related to unmeasured confounders are required for the unbiasedness of the natural direct and indirect effects estimates. We focused on the assumption most likely to be violated of no unmeasured confounders of the mediator-outcome relationship and showed that our findings were stable. Although it is difficult to rule out violation of all other assumptions, the inclusion of model controls for socio-demographic characteristics, year of delivery, obstetrical conditions, fetal conditions, intrapartum conditions, and other pre-existing conditions may have reduced the possibility of unmeasured confounding.

Lastly, while we attempted to identify women in labor, we did not have primary data to account for a patient's length of time in labor or clinical events during labor that might have contributed to the development of severe morbidity. For example, induction of labor was not included as a covariate, yet it is associated with increased rates of maternal sepsis and hemorrhage, both of which can be classified as severe maternal morbidity. ${ }^{[16]}$

In summary, we used a mediation approach to estimate the risk of severe maternal morbidity associated with key maternal health conditions, finding that the conditions with the largest ORs were heart disease and hypertension, and that generally the increased risk mediated by NTSV CD in laboring women was low. These findings direct attention to the identification of antepartum opportunities for both primary and secondary prevention efforts in these at-risk populations.

\section{ACKNOWLEDGEMENTS}

Financial support for this work was provided by federal Title V MCH block grant funding from the California Department of Public Health, Maternal, Child and Adolescent Health Division (Contract No. 01-15166), and by the Agency for Healthcare Research and Quality, contract number 5R01HS017713.
[2] Creanga AA, Berg CJ, Ko JY, et al. Maternal mortality and morbidity in the United States: where are we now? Journal of Womens Health 2014; 23(1): 3-9. PMid:24383493 http://dx. doi .org/10. 1089 /jwh. 2013.4617

[3] Callaghan WM, Creanga AA, Kuklina EV. Severe maternal morbid- 
ity among delivery and postpartum hospitalizations in the United States. Obstetrics and Gynecology. 2012; 120: 1029-1036. http: //dx.doi.org/10.1097/aog.0b013e31826d60c5

[4] Kuklina EV, Meikle SF, Jamieson DJ, et al. Severe obstetric morbidity in the United States: 1998-2005. Obstetrics and Gynecology. 2009; 113: (2, Part 1): 293-299. PMid:19155897 http: //dx.doi.org/10.1097/AOG.0b013e3181954e5b

[5] Grobman WA, Bailit JL, Rice MM, et al, for the Eunice Kennedy Shriver National Institute of Child Health and Human Development (NICHD) Maternal-Fetal Medicine Units (MFMU) Network. Frequency of and factors associated with severe maternal morbidity. Obstetrics and Gynecology. 2014; 123: 804-810. PMid:24785608 http://dx.doi.org/10.1097/AOG.0000000000000173

[6] Wen SW, Huang L, Liston R, et al for the Maternal Health Study Group, Canadian Perinatal Surveillance System. Severe maternal morbidity in Canada, 1991-2001. Canadian Medical Association Journal. 2005; 173(7): 759-764. PMid:16186582 http://dx.doi . org/10.1503/cmaj. 045156

[7] Lutomski JE, Greene RA, Byrne BM. Severe maternal morbidity during childbirth hospitalisation: a comparative analysis between the Republic of Ireland and Australia. European Journal of Obstetrics, Gynecology and Reproductive Biology. 2012; 163: 148153. PMid:22640728 http://dx.doi.org/10.1016/j . ejogrb. 2012.05 .003

[8] Gray KE, Wallace ER, Nelson KR, et al. Population-based study of risk factors for severe maternal morbidity. Paediatrics and Perinatal Epidemiology. 2012; 26: 506-514. PMid:23061686 http: $/ / \mathrm{dx}$.doi.org/10.1111/ppe.12011

[9] Berg CJ, MacKay AP, Cheng Q, et al. Overview of maternal morbidity during hospitalization for labor and delivery in the United States: 1993-1997 and 2001-2005. Obstetrics and Gynecology. 2009; 113(5): 1075-1081. PMid:19384123 http://dx.doi.org/10.1097/AOG .0b013e3181a09f c0

[10] Fridman M, Korst LM, Chow J, et al. Trends in maternal morbidity before and during pregnancy in California. American Journal of Public Health. 2014; 104(Suppl): 1: S49-S57.

[11] Johnson JL, Farr SL, Dietz PM, et al. Trends in gestational weight gain: the Pregnancy Risk Assessment Monitoring System, 20002009. American Journal of Obstetrics and Gynecology. 2015; 212 : 806.e1-8. PMid:25637844 http://dx.doi.org/10.1016/j.ajo g. 2015.01.030

[12] Huisman CM, Zwart JJ, Roos-Hesselink JW, et al. Incidence and predictors of maternal cardiovascular mortality and severe morbidity in the Netherlands: a prospective cohort study. PLOS ONE. 2013; 8(2): e56494. PMid:23457576 http://dx.doi.org/10.1371/j ournal.pone. 0056494

[13] Zwart JJ, Richters JM, de Vries JIP, et al. Severe maternal morbidity during pregnancy, delivery and puerperium in the Netherlands: a nationwide population-based study of 371,000 pregnancies. British Journal of Obstetrics and Gynaecology. 2008; 115: 842850. PMid:18485162 http://dx.doi.org/10.1111/j.1471-0 528.2008.01713.x

[14] Geller SE, Cox SM, Kilpatrick SJ. A descriptive model of preventability in maternal morbidity and mortality. J Perinatol. 2006; 26: 7984. PMid:16407964 http://dx.doi.org/10.1038/sj.jp.721 1432

[15] Gregory KD, Jackson S, Korst L, et al. Cesarean versus vaginal delivery: whose risks? Whose benefits? American Journal of Perinatology. 2012; 29(1): 7-18. PMid:21833896 http://dx.doi.org/10.10 $55 / \mathrm{s}-0031-1285829$

[16] Liu S, Liston RM, Joseph KS, et al. Maternal mortality and severe morbidity associated with low-risk planned cesarean delivery versus planned vaginal delivery at term. Canadian Medical Association Journal. 2007; 176(4): 455-460. PMid:17296957 http: //dx.doi.org/10.1503/cmaj.060870

[17] Pallasmaa N, Ekblad U, Gissler M. Severe maternal morbidity and the mode of delivery. Acta Obstetricia et Gynecologica Scandinavica. 2008; 86: 662-668. PMid:18568466 http://dx.doi.org/10.10 $80 / 00016340802108763$

[18] Pacheco AJC, Katz L, Souza ASR, et al. Factors associated with severe maternal morbidity and near miss in the Sao Francisco Valley, Brazil: a retrospective cohort study. BMC Pregnancy and Childbirth 2014; 14: 91. PMid:24576223 http://dx.doi.org/10.1186/1 471-2393-14-91

[19] Schisterman EF, Cole SR, Platt RW. Overadjustment bias and unnecessary adjustment in epidemiologic studies. Epidemiology. 2009; 20(4): 488-495. PMid:19525685 http://dx.doi.org/10.1097 /EDE.0b013e3181a819a1

[20] Gilbert WM, Nesbitt TS, Danielsen B. The cost of prematurity: quantification by gestational age and birthweight. Obstetrics and Gynecology. 2003: 102: 488-492. http://dx.doi.org/10.1016/S0029 $-7844(03) 00617-3$

[21] The Joint Commission. Perinatal Care Measure Set (PC-02): Cesarean Section. Nulliparous women with a term, singleton baby in a vertex position delivered by cesarean section. Specifications Manual for Joint Commission National Quality Measures (v2015A1). Available from: https://manual.jointcommission.org/release s/TJC2015A1/MIF0167.html

[22] Korst L, Fridman M, Lu M, et al. Monitoring childbirth morbidity using hospital discharge data: further development and application of a composite measure. American Journal of Obstetrics and Gynecology. 2014; 211(3): 268: e1-e16.

[23] Korst LM, Gregory KD, Gornbein JA. Elective primary cesarean delivery: accuracy of administrative data. Paediatric and Perinatal Epidemiology. 2004; 18(2): 112-119. http://dx.doi.org/10.11 $11 / j .1365-3016.2003 .00540 \cdot x$

[24] Kotelchuck M. An evaluation of the Kessner Adequacy of Prenatal Care Index and a proposed adequacy of prenatal care utilization index. American Journal of Public Health. 1994; 84: 1414-1420. PMid:8092364 http://dx.doi.org/10.2105/AJPH. 84.9.141 4

[25] Valeri L, VanderWeele TJ. Mediation analysis allowing for exposure-mediator interactions and causal interpretation: theoretical assumptions and implementation with SAS and SPSS macros. Psychological Methods. 2013; 18(2): 137-150. PMid:23379553 http://dx.doi.org/10.1037/a0031034

[26] Hosmer DW, Lemeshow S. A goodness-of-fit test for the multiple logistic regression model. Communications in Statistics. 1980; A10: 1043-1069. http://dx.doi.org/10.1080/03610928008 827941

[27] Ananth CV, VanderWeele TJ. Placental abruption and perinatal mortality with preterm delivery as a mediator: disentangling direct and indirect effects. American Journal of Epidemiology. 2011; 174(1): 99108. PMid:21430195 http://dx.doi.org/10.1093/aje/kwr04 5

[28] Mendola P, Mumford SL, Männistö TI, et al. Controlled direct effects of preeclampsia on neonatal health after accounting for mediation by preterm birth. Epidemiology. 2015; 26(1): 17-26. PMid:25437315 http://dx.doi.org/10.1097/EDE.0000000000000213

[29] VanderWeele TJ. Bias formulas for sensitivity analysis for direct and indirect effects. Epidemiology. 2010; 21(4): 540551. PMid:20479643 http: //dx. doi .org/10.1097/EDE. 0b013 e3181df191c 
[30] Subramaniam A, Jauk VC, Goss AR, et al. Mode of delivery in women with Class III obesity: planned cesarean compared with induction of labor. American Journal of Obstetrics and Gynecology. 2014; 211: 700.e1-9. PMid:24956550 http://dx.doi.org/10. 1016/j.ajog.2014.06.045

[31] Goffman D, Mdden RC, Harrison EA, et al. Predictors of maternal mortality and near-miss maternal morbidity. J Perinatol. 2007; 27(10): 597-601. PMid:17703181 http://dx.doi.org/10.1038/sj.jp .7211810

[32] Lindquist AC, Kurinczuk JJ, Wallace EM, et al. Risk factors for maternal morbidity in Victoria, Australia: a population-based study.
BMJ Open. 2015; 5(8): e007903. PMid:26307615 http://dx. doi .org/10.1136/bmjopen-2015-007903

[33] Siu SC, Sermer M, Colman JM, et al. Cardiac Disease in Pregnancy (CARPREG) Investigators. Prospective multicenter study of pregnancy outcomes in women with heart disease. Circulation. 2001; 104(5): 515-21. PMid:11479246 http://dx.doi.org/10.1161 /hc3001.093437

[34] Davies GA, Herbert WN. Congenital Heart Disease in Pregnancy. J Obstet Gynaecol Can. 2007; 29: 409-414. PMid:17493372

[35] Martin JA, Hamilton BE, Osterman MJK, et al. Births: final data for 2013; National Vital Statistics Reports. 2015; 64(1): 1-65. 